\title{
Evaluation of tritium retention in plasma facing components during JET tritium operations
}

\section{JET Contributors}

2021-12

JET Contributors, Widdowson , A , Likonen , J \& Mizohata , K 2021 , ' Evaluation of tritium retention in plasma facing components during JET tritium operations ' , Physica Scripta, vol. 96 , no. 12 , 124075 . https://doi.org/10.1088/1402-4896/ac3b30

http://hdl.handle.net/10138/339664

https://doi.org/10.1088/1402-4896/ac3b30

cc_by

publishedVersion

Downloaded from Helda, University of Helsinki institutional repository.

This is an electronic reprint of the original article.

This reprint may differ from the original in pagination and typographic detail.

Please cite the original version. 
PAPER • OPEN ACCESS

\section{Evaluation of tritium retention in plasma facing components during JET tritium operations}

To cite this article: Anna Widdowson et al 2021 Phys. Scr. 96124075

View the article online for updates and enhancements.
You may also like

The First CHIME/FRB Fast Radio Burst Catalog

The CHIME/FRB Collaboration, Mandana

Amiri, Bridget C. Andersen et al.

The Variability of the Black Hole Image in M87 at the Dynamical Timescale Kaushik Satapathy, Dimitrios Psaltis, Feryal Özel et al.

Search for Multi-flare Neutrino Emissions in $10 \mathrm{yr}$ of IceCube Data from a Catalog of Sources

R. Abbasi, M. Ackermann, J. Adams et al. 


\section{Physica Scripta}

\section{PAPER}

CrossMark

\section{Evaluation of tritium retention in plasma facing components during JET tritium operations}

RECEIVED

22 June 2021

REVISED

30 September 2021

ACCEPTED FOR PUBLICATION

18 November 2021

PUBLISHED

15 December 2021

Original content from this work may be used under the terms of the Creative

Commons Attribution 4.0 licence.

Any further distribution of this work must maintain

attribution to the author(s) and the title of

the work, journal citation and DOI.
Anna Widdowson ${ }^{1}$ (10) , J Paul Coad ${ }^{1}$ (D), Yevhen Zayachuk $^{1}$, Ionut Jepu $^{2}$ (iD, Eduardo Alves $^{3}$ (i), Norberto Catarino $^{3}$ (1D, Victoria Corregidor ${ }^{3}$, Matej Mayer ${ }^{4}$ (D) , Stepan Krat ${ }^{4,5}$ (D) , Jari Likonen ${ }^{6}$, Kenichiro Mizohata $^{7}$, Chris Rowley $^{1}\left(\mathbb{D}\right.$, Miroslaw Zlobinski $^{8}$ (D), Marek Rubel $^{9}$ (D) David Douai $^{10}$, Kalle Heinola $^{11}$ (i), Tom Wauters ${ }^{12}$ (D), Laura Dittrich ${ }^{9}$ (i), Sunwoo Moon ${ }^{9}$ (D), Per Petersson ${ }^{9}$ (i), Aleksandra Baron-Wiechec ${ }^{13}$ (D) Liga Avotina $^{14}$ (D) JET Contributors ${ }^{15}$

1 United Kingdom Atomic Energy Authority, Culham Centre for Fusion Energy, Culham Science Centre, Abingdon, OXON, OX14 3DB, United Kingdom

2 National Institute for Laser, Plasma and Radiation Physics, Magurele 077125, Romania

3 IPFN, Instituto Superior Técnico, Universidade de Lisboa, 1049-001, Lisboa, Portugal

4 Max-Planck Institut für Plasmaphysik, 85748 Garching, Germany

National Research Nuclear University MEPhI, 115409 Moscow, Russia

6 VTT Technical Research Centre of Finland, P.O.Box 1000, FIN-02044 VTT, Finland

University of Helsinki, PO Box 64, FI-00560 Helsinki, Finland

8 Forschungszentrum Jülich GmbH, Institut für Energie- und Klimaforschung - Plasmaphysik, Partner of the Trilateral Euregio Cluster (TEC), 52425 Jülich, Germany

9 Royal Institute of Technology (KTH), Association EURATOM-VR, 10044 Stockholm, Sweden

${ }^{10}$ CEA, IRFM, F-13108, St-Paul-Lez-Durance, France

${ }^{11}$ International Atomic Energy Agency, Vienna International Centre, PO Box 100, 1400 Vienna, Austria

${ }^{12}$ Laboratory for Plasma Physics, LPP-ERM/KMS, B-1000 Brussels, Belgium

${ }^{13}$ Guangdong Technion-Israel Institute of Technology, Shantou, 515063, People's Republic of China

${ }^{14}$ University of Latvia, Institute of Chemical Physics, Riga, Latvia

${ }^{15}$ See the author list of 'Overview of JET results for optimising ITER operation' by J. Mailloux et al. to be published in Nuclear Fusion Special issue: Overview and Summary Papers from the 28th Fusion Energy Conference (Nice, France, 10-15 May 2021) IAEA FEC fusion portal

E-mail: anna.widdowson@ukaea.uk

Keywords: JET, fuel retention, tritium

\section{Abstract}

An assessment of the tritium (T) inventory in plasma facing components (PFC) during JET T and deuterium-tritium (DT) operations is presented based on the most comprehensive ex situ fuel retention data set on JET PFCs from the 2015-2016 ILW3 operating period is presented. The global fuel retention is $4.19 \times 10^{23} \mathrm{D}$ atoms, $0.19 \%$ of injected fuel. The inner divertor remains the region of highest fuel retention (46.5\%). The T inventory in PFCs at the end of JET operations is calculated as $7.48 \times 10^{22}$ atoms and is informative for accountancy, clean-up efficacy and waste liability assessments. The T accumulation rate at the upper inner divertor during JET DT operations has been used to assess the requirements and frequency of operation of a new laser induced desorption diagnostic to be installed on JET for the final DT experiments in 2023.

\section{Introduction}

JET started its most recent and final tritium operating phase in 2021, with $100 \%$ tritium and tritium-protium ('hydrogen') plasmas and will move to deuterium-tritium (DT) operations from mid-2021. The DT operations will comprise two experimental campaigns, DTE2 in 2021 and DTE3 in 2023. Details of the experimental objectives of DT operations can be found in [1]. These are the first DT experiments since the DT experiments in 1997 (DTE1) [2]. Between DTE1 and DTE2 JET has operated with deuterium and protium. The operation in tritium will result in tritium being retained in-vessel, in particular in plasma facing components. This has implications for the accountancy of tritium, safety case considerations and the final waste liability of nuclear materials arising from JET. 

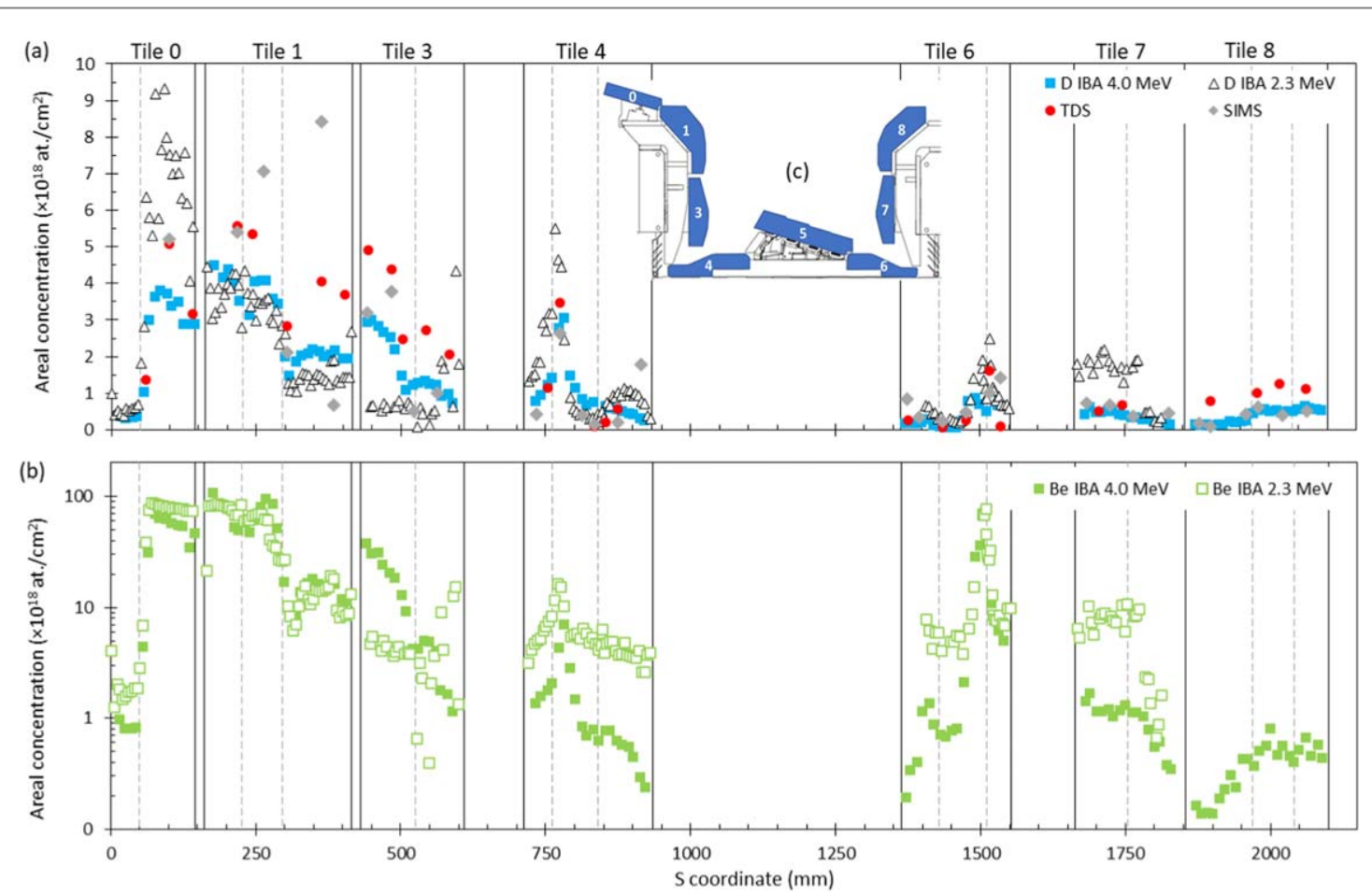

Figure 1. (a) Deuterium areal concentrations on 2015-2016 ILW3 divertor tiles measured using IBA at 4.0 MeV, $2.4 \mathrm{MeV}$ and 2.3 MeV ${ }^{3} \mathrm{He}^{+}$beam, TDS and SIMS. (b) Beryllium areal concentration measured using IBA at $4.5 \mathrm{MeV}, 3.0 \mathrm{MeV}$ and $2.3 \mathrm{MeV} \mathrm{H}^{+}$beam. (c) Cross section of JET divertor showing tile numbering. The s-coordinates ( $\mathrm{mm}$ ) system runs along the surface profile of the tiles starting at $s=0$ at the uppermost left-hand corner of Tile 0 and finishing at the uppermost right-hand corner of Tile 8 .

Since 2011, when JET started operating with the all metal ITER-Like Wall (JET-ILW) [3], plasma facing components have been periodically removed from the JET vessel for analysis in a laboratory setting, i.e., ex situ analysis. The components are exposed to a varied experimental campaign with $\sim 20 \mathrm{~h}$ of plasma operations [4], consisting in the order of 3000 JET pulses with $\sim 20$ s discharge time per pulse over a 12-18 month period. The results from these components have provided data on ex situ long term fuel retention, experimental evidence for the material migration processes in JET, demonstrated the reduction in fuel retention, erosion and deposition for JET-ILW in line with JET experiments [5, 6] and provided benchmarking data for modelling [7, 8]. In this paper the fuel retention data associated with the 2015-2016 ILW3 operating period are presented. It brings together for the first time the results from ion beam analysis techniques, thermal desorption techniques and secondary ion mass spectroscopy to evaluate the global retention in JET for this period from all analysed areas of the vessel, providing the most comprehensive and recent summary of fuel retention for JET. From this data the global retention of fuel and distribution in different regions of the vessel are established and compared with previous results reported for the 2011-2012 ILW1 operating period [9]. Furthermore, fuel retention is used to assess the potential tritium retention following ongoing tritium operations in JET and associated waste liability assessments. The data is also used to aid in the design solution and operating schedule of a new laser induced desorption diagnostics to be installed in JET prior to the final deuterium-tritium operations in 2023 (DTE3). This diagnostic will demonstrate the monitoring of fuel retention in plasma facing components within in the fusion vessel, i.e., 'in situ analysis' as foreseen in ITER [10].

\section{Experimental procedure}

Plasma Facing Components (PFCs) and remote area diagnostics have been removed from JET following three operating periods of JET; 2011-2012 ILW1, 2013-2014 ILW2 and 2015-2016 ILW3 and comprehensive analysis has been completed, i.e., ex situ analysis. This paper concentrates on fuel retention analysis from ILW3.

Discussions about impurity deposition rates and comparison of techniques are not included here. Results from three analysis techniques are presented in this assessment of global retention in JET; Ion Beam Analysis (IBA), Thermal Desorption Spectrometry (TDS) and Secondary Ion Mass Spectrometry (SIMS). In figure 1 the IBA data from two facilities are presented: IPFN Instituto Superior Técnico, Portugal and IPP Garching, Germany. The facility at IPFN has capability for $2.3 \mathrm{MeV}$ for ${ }^{3} \mathrm{He}^{+}$and $\mathrm{H}^{+}$beams, using WinNDF to analyse data. The facility at IPP has capability for $2.4 \mathrm{MeV}^{3} \mathrm{He}^{+}$for NRA and $3.0 \mathrm{MeV}$ and $4.5 \mathrm{MeV} \mathrm{H}^{+}$for backscattering data 
depending on deposit thickness, using SIMNRA to analyse data. Both facilities are described in detail in [11]. In both cases the data provided is to an analysis depth of $\sim 1 \times 20 \mathrm{at} \mathrm{cm}^{-2}$, which represents the maximum penetration of the ${ }^{3} \mathrm{He}^{+}$beam assuming beryllium rich deposits with Be density $=1.8 \mathrm{~g} \mathrm{~cm}^{-3}$. TDS data are obtained from the facility based at CCFE, United Kingdom using a ramp rate of $10 \mathrm{~K} \mathrm{~min}^{-1}$ to $775^{\circ} \mathrm{C}(\mathrm{Be})$ or $1000^{\circ} \mathrm{C}$ (W and CFC), $1 \mathrm{~h}$ anneal and non-controlled ramp down [12]. SIMS is performed at VTT, Finland using $\mathrm{O}^{+2}$ [13]. All systems have capability for handling tritium $(\mathrm{T})$ and beryllium $(\mathrm{Be})$ contaminated samples. The data for divertor PFCs is a mix of previously published and un-published data. Previously published data are $[14,15]$ for IBA and [12] for TDS and SIMS. The figure demonstrates that deposition and retention in the divertor are well characterised and understood and therefore the data is used to underpin fuel retention calculations as discussed in sections 3 and 4 .

The global retention value has been calculated using the divertor data presented in figure 1(a) with additional data from main chamber beryllium (Be) limiter tiles [4], Be coated inconel (Be-inconel) recessed Inner Wall Cladding tiles (IWC) [16], Tungsten coated Carbon Fibre Composite (W-CFC) recessed inner limiter tiles, passive diagnostics from the outer recessed wall of the vacuum vessel [17] and remote divertor regions [17, 18]. Data for these analyses include IBA techniques from VR, Sweden and University of Helsinki, Finland with facilities described in [11]. As for the error that can be expected from this type of global extrapolation calculation, the standard deviation of the fuel retention data from all analysis sources is $39 \%$ for the inner divertor and $45 \%$ for the outer divertor, therefore errors in average values presented are of this order.

The aim of this paper is to provide the most up to date assessment of retention fraction in order to aid in predicting T retention during JET T operations. However in order to compare these results from ILW3 with previous results from ILW1 it is necessary to provide a set of data following the methodology presented in [9]. The differences in data sets for the latest ILW3 assessment presented here and previous ILW1 methodology are shown in parentheses \{\} in table 1 and throughout the text and are summarised as follows.

\subsection{Tile surface areas}

In the most part the same areas for each component type are used, except in the case of IWC which has been reduced from $11.2 \mathrm{~m}^{2}$ to $7.2 \mathrm{~m}^{2}$ to reflect a more recent assessment and data presented in [16]. The 2011-2016 ILW1-3 IWC data from [16] is scaled by the plasma operation time to provide a retention value for ILW3.

\subsection{Retention in main chamber tile gaps}

The retention calculation in [9] does not take into account retention in gaps and castellation cuts in the beryllium main chamber tiles of JET. To date the complete assessment in retention in gaps for ILW3 main chamber Be PFCs has not been completed. However it was shown in $[19,20]$ that gaps account for up to $50 \%$ of retention in the main chamber. In order to provide more complete analysis this fraction has been applied to the data in table 1.

\subsection{Retention on tungsten Tile 5}

As for retention in gaps discussed above the retention calculation in [9] does not take into account retention on the plasma facing surface of W components (lamellae) on Tile 5. To date analysis results for ILW3 are not available, therefore it is assumed to be $1 \%$ of the divertor retention as shown in [19].

\subsection{Retention in remote areas of divertor}

The latest Nuclear Reaction Analysis (NRA) and Elastic Recoil Detection Analysis (ERDA) datasets available for a variety of components from the inner and outer divertor corners and under Tile $5 \mathrm{~s}$ are included in the latest analysis results. For the comparison of ILW1 and ILW3 only NRA data on a single component type (louvre clip) is taken into account.

\subsection{Calculation of gas injection in atoms}

One source of error in the determination of global retention as a function of injected fuel is the conversion of molecular gas injection in bar-litres (barl) to the number of hydrogen atoms. This requires an assumption about the temperature of the gas injection volume. For the ILW1 fuel retention reported in [9] the gas injection value $1.67 \times 10^{26} \mathrm{D}$ (5406 barl) from the main chamber gas injection modules (GIMS) was calculated at the vessel operating temperature of $473 \mathrm{~K}$. However, gas injection conversions for JET operations are more usually done at $300 \mathrm{~K}$, i.e., room temperature, where temperature measurements of the calibrated gas volumes are available. This results in the gas injection for ILW1 coming to $2.61 \times 10^{26} \mathrm{D}$ atoms. For ILW3 the D gas injected was 4573 barl, giving $1.4 \times 10^{26}$ or $2.21 \times 10^{26} \mathrm{D}$ atoms calculated at $473 \mathrm{~K}$ and $300 \mathrm{~K}$ respectively. In general this paper will work with the conversion at $300 \mathrm{~K}$. The implications of this for fuel retention data is discussed in section 3. 
Table 1. Summary of fuel retention on plasma wall components making up the JET-ILW after 2015-2016 operating period. The results combine un-published and previously published data.

\begin{tabular}{|c|c|c|c|c|c|}
\hline Location in vessel & Material & $\begin{array}{l}\text { Total area } \\
\quad\left(\mathrm{m}^{2}\right)\end{array}$ & $\begin{array}{l}\text { ILW3 D atoms } \\
\quad\left(\times 10^{22}\right)\end{array}$ & $\begin{array}{l}\% \text { of global } \\
\text { retention }\end{array}$ & $\begin{array}{l}\text { Estimate of T Inventory } \\
\qquad\left(\times 10^{22}\right)\end{array}$ \\
\hline Upper Dump plate $^{\mathrm{a}}$ & $\mathrm{Be}$ & 6.05 & 1.60 & $3.8\{4.1\}$ & 0.29 \\
\hline Inner Wall Guard Limiter ${ }^{a}$ & $\mathrm{Be}$ & 4.75 & 1.20 & $2.9\{3.0\}$ & 0.21 \\
\hline Recessed Inner Wall & $\mathrm{Be} / \mathrm{W}$ & $10.05\{15\}$ & $3.99\{5.90\}$ & $9.5\{15.0\}$ & 0.71 \\
\hline recessed inner limiters ${ }^{\mathrm{b}}$ & $\mathrm{W}-\mathrm{CFC}$ & $2.85\{4.0\}$ & $1.56\{2.19\}$ & $3.7\{5.6\}$ & 0.28 \\
\hline recessed inner wall ${ }^{\mathrm{C}}$ & $\begin{array}{c}\text { Be-inconel/ } \\
\text { W-CFC }\end{array}$ & $\begin{array}{c}5.36 / \\
1.84\{11.0\}\end{array}$ & $2.43\{3.71\}$ & $5.8\{9.4\}$ & 0.43 \\
\hline Outer Poloidal Limiter ${ }^{\mathrm{a}}$ & $\mathrm{Be}$ & 10.08 & 3.20 & $7.6\{8.1\}$ & 0.57 \\
\hline Recessed Outer Wall $^{\mathrm{d}}$ & Inconel & 44 & 0.44 & $1.0\{1.1\}$ & 0.08 \\
\hline Main Chamber Gaps ${ }^{\mathrm{e}}$ & $\mathrm{Be}$ & $100\{-\}$ & $5.22\{-\}$ & $12.4\{-\}$ & 0.93 \\
\hline Divertor ${ }^{\mathrm{b}, \mathrm{f}}$ & $\mathrm{W}$ & $20.27\{16.97\}$ & $25.3\{25.1\}$ & $60.5\{63.7\}$ & 4.52 \\
\hline inner divertor (Tiles $0,1,3,4$ ) & W-CFC & 8.73 & 19.5 & $46.5\{49.5\}$ & 3.47 \\
\hline outer divertor (Tiles $6,7,8$ ) & W-CFC & 8.24 & 5.61 & $13.4\{14.2\}$ & 1.00 \\
\hline Tile $5^{\mathrm{g}}$ & $\mathrm{W}$ & $3.30\{-\}$ & $0.25\{-\}$ & $0.6\{-\}$ & 0.04 \\
\hline Remote areas in divertor ${ }^{\mathrm{b}, \mathrm{h}}$ & SS/Inconel & 2.87 & $0.95\{1.96\}$ & $2.3\{5.0\}$ & 0.17 \\
\hline inner corner & SS/Mo/Inconel & 0.71 & $0.48\{1.27\}$ & $1.1\{3.2\}$ & 0.09 \\
\hline outer corner & SS/Mo/Inconel & 1.15 & $0.34\{0.69\}$ & $0.8\{1.8\}$ & 0.06 \\
\hline under Tile 5 & SS/Mo/Inconel & $1.01\{-\}$ & $0.13\{-\}$ & $0.3\{-\}$ & 0.02 \\
\hline Total & & $\begin{array}{c}198.07 \\
\{98.72\}\end{array}$ & $41.9\{39.4\}$ & 100 & 7.48 \\
\hline
\end{tabular}

${ }^{a}[4]$.

${ }^{\mathrm{b}}$ un-published data.

${ }^{c}[16]$.

${ }^{\mathrm{d}}$ [17].

e contribution taken as $50 \%$ of main chamber retentions $[19,20]$.

f $[14,15]$.

$\mathrm{g}$ contribution taken as $1 \%$ of divertor retention [19]. The areas on divertor tiles shown in column 3 are scaled by 0.85 of actual surface area to take account for shadowing at the leading edge where there is little of no deposition. Data in parentheses \{\} are calculated according to assumptions in [9] to allow direct comparison of retention data. The last column provides an ex situ tritium retention based on the throughput of $3.94 \times 10^{25} \mathrm{~T}$ atoms during T \& DT operations in JET. This is expected to be an upper limit as it does not take into account in situ cleaning prior to the removal of components. The materials of the components are included to aid in assignment of waste liability. ${ }^{\mathrm{h}}[17,18]$.

The T throughput presented here includes (i) T injected into the machine to date $\left(9.47 \times 10^{24} \mathrm{~T}\right.$ atoms $/ 47.4$ $\mathrm{g}$ at $300 \mathrm{~K}$ ) for JET pulse numbers (JPN) 98043 to 98925 from GIMs and neutral beam injection (NBI)), and (ii) estimated T throughput for the remaining T operations; 12 days of T, 39 days DTE2 and 12 days DTE3. In each case $4 \mathrm{~g} / 7.99 \times 10^{23}$ atoms $\mathrm{T}$ is assumed to be injected in T operations, and $2 \mathrm{~g} / 3.99 \times 10^{23}$ atoms in DT operations. This is based on operational limits per day of $11 \mathrm{~g} \mathrm{~T}$ usage, of which $4 \mathrm{~g}(\sim 0.33)$ is injected into the main vessel during T operations. The remaining $7 \mathrm{~g}(\sim 0.67)$ goes to the Neutral Injector Boxes (NIBs). For DT plasmas operational overheads related to $\mathrm{T}$ management are likely to limit the total number of plasma pulses per day, and therefore $2 \mathrm{~g} \mathrm{~T}$ per day is assumed. This results in a total T throughput into the main vessel of $3.94 \times 10^{25}$ atoms, $197 \mathrm{~g}$. These values are significantly lower than a previous estimate [21] where it was assumed $9.9 \mathrm{~g}(0.9)$ injected into the vessel and $1.1 \mathrm{~g}(0.1)$ in the NIBs with 32 days of T and 64 days of DT giving a throughput of $950 \mathrm{~g}$. The consequence is that the T inventory values in this paper will be less than previously reported.

\section{Results}

The results for the $\mathrm{D}$ fuel retention and Be deposition in the divertor are shown in figure 1 . The overall picture of material migration is similar to that of ILW1, where Be eroded in the main chamber migrates in the scrape off layer to the top of the inner divertor region. Once deposited it tends to remain in this region and does not migrate to remote divertor corners, as was the case for the JET Carbon wall (JET-C), where carbon-hydrogen chemistry provided an additional erosion mechanism and subsequent erosion-redeposition step-wise transport to the divertor corners, remote from the plasma.

The best estimate of the $\mathrm{D} / \mathrm{Be}$ ratio can be taken in the s-coordinate region 60-290 mm where the thickest Be deposits are located on Tile 0 and the top of Tile 1 . The thickness of the deposits is similar to the interaction depth from the IBA and therefore is not greatly influenced by the W tile surface 'substrate' below. In thick 
deposits the $\mathrm{C}$ concentration is found to be of the same order as the $\mathrm{D}$ concentration as shown in [22] and [23]. Taking the average of data from these sources $\mathrm{D} / \mathrm{Be}=0.07 \pm 0.03$ and $\mathrm{C} / \mathrm{Be}=0.05 \pm 0.02$ for the interaction depth $\sim 8 \mu \mathrm{m}$, for Be density $=1.8 \mathrm{~g} \mathrm{~cm}^{-3}$.

Including D retention data from figure 1 and other areas of the vessel, as discussed in section 2 , the retention for each region was determined and is summarised in table 1 . The total global $\mathrm{D}$ retention is found to be $4.19 \times 10^{23} \mathrm{D}$ atoms $\left\{3.94 \times 10^{23} \mathrm{D}\right.$ for comparison with [9] $\}$. Assuming the D injection of $2.21 \times 10^{26} \mathrm{D}$ atoms at $300 \mathrm{~K}$ this gives a retention fraction of $0.19 \% \pm 0.08 \%\{0.18 \%\}$. To compare with ILW1 global retention data presented in [9] the $0.23 \%$ retention calculated at $473 \mathrm{~K}$ reduces to $0.14 \%$ when calculated at $300 \mathrm{~K}$ using gas injection values discussed in section 2 . The implications are that the overall retention as a fraction of injected fuel are similar for ILW1 and ILW3 and that the global retention value for ILW1 is lower than previously reported.

The global retention rate for ILW3 normalised to the divertor plasma time $\left(18.5 \mathrm{~h} / 6.7 \times 10^{4} \mathrm{~s}\right)$, i.e., the total time where an $\mathrm{x}$-point is formed and the plasma strikes the inner and outer divertor tiles, is $6.3 \times 10^{18} \mathrm{D}$ atoms/ $\mathrm{s}\left\{5.9 \times 10^{18} \mathrm{D}\right.$ atoms $\left./ \mathrm{s}\right\}$. For ILW1 it is $7.9 \times 10^{18} \mathrm{D}$ atoms $/ \mathrm{s}$ normalised to the divertor plasma time $\left(13 \mathrm{~h} / 4.7 \times 10^{4} \mathrm{~s}\right)$ [9]. Irrespective of the retention data set used for ILW3 the global fuel deposition rate has decreased in comparison to ILW1. The ratios of the retention fraction and retention rates for ILW1:\{ILW3 $\}$ are $1:\{1.3\}$ and $1:\{0.7\}$ which will represent the predominant plasma scenarios for ILW3. Such differences are discussed in [5], where a range of plasma scenarios with different fueling rates, auxiliary heating, pumping conditions result in different retention fractions and retention rates.

The divertor retention fraction dominates the main chamber, with the inner divertor remaining the highest region of deposition. The remote corner deposition has reduced in ILW3 accounting for 3.6\% $\{7.3 \%\}$ of divertor retention in ILW3 compared with $16.7 \%$ in ILW1. The results show that the recessed inner wall can contribute a significant fraction of the global retention with the latest retention data for Be-inconel IWC [16] and W-CFC recessed limiter tiles contributing 10\%.

Overall, the retention fraction for ILW3 is similar to ILW1 and reaffirms the efficacy of the all-metal JETILW at reducing fuel retention compared with the JET-C where retention was found to be $4 \%$, i.e., $66 \mathrm{~g} \mathrm{D}$ retained and $1800 \mathrm{~g}$ injected in the MkII-SRP operations 2001-2004 [24]. For JET-ILW, the retention fraction has decreased by at least an order of magnitude compared with JET-C.

\section{Discussion}

JET is operating with 100\% T and T-hydrogen $(\mathrm{H})$ gas mixtures from March-June 2021. This is followed by DT operations (DT-experiment 2 (DTE2)) until September 2021 and DTE3 in early 2023. DTE2 and DTE3 will be followed by $\mathrm{D}$ operations to reduce T inventory in the vessel. This discussion considers how the long-term global retention data determined from ex situ analysis may be applied to assess T accumulation in JET, the efficacy of T removal experiments and use of a future laser induced desorption diagnostic on JET. Finally, the results can be used to estimate $\mathrm{T}$ inventory for waste liability and waste reduction experiments.

\subsection{In-situ retention and ex situ long-term retention}

As previously reported ex situ long-term fuel retention assessed on components removed from JET yield a lower fuel retention assessment than in situ retention measured by gas balance during operations [5]. In the vessel there is a dynamic retention cycle-fuel loading during plasma pulses and out-gassing after plasma pulses are completed. The in situ deuterium retention normalised to the divertor plasma operation time is in the range $0.2-1.5 \times 10^{20} \mathrm{D}$ atoms/s dependant on the plasma scenario [5] during ILW1. To provide a representative comparison the ex situ retention rates for ILW1 and ILW3 are $7.9 \times 10^{18} \mathrm{D}$ atoms $/ \mathrm{s}$ and $6.3 \times 10^{18} \mathrm{D}$ atoms $/ \mathrm{s}$ when normalised to the divertor plasma time. Comparing ILW1 data the in situ retention rate determined for individual plasma scenarios is a factor 3-24 higher than the ex situ retention rate determined from a global campaign average. This range is wide as the in situ retention rates are highly dependent on the individual plasma scenario. The largest differences arising from L-mode plasmas with $0.5 \mathrm{MW}$ RF heating with turbomolecular pumping and type III ELMy H-mode plasmas with 5.0 MW heating by NBI [5], an unlikely operating condition for JET during T operations. Therefore, a more realistic range is 3-11. This is consistent with a wider study of gas balance and fuel retention in fusion devices indicates that in situ retention is generally 3-6 times higher than ex situ values [25]. Given the varied plasma operations programme at JET, the average ex situ retention will lie between these extremes. In addition, as more PFCs are analysed a more complete picture with increasing inventory is established, therefore a factor 4 is applied between in situ and ex situ retention in the T retention assessments in later sections.

For ILW1 and ILW3 there were no cleaning/isotope exchange experiments at the end of the operating periods to take into consideration. Therefore, the difference will be a combination of in situ and ex situ out- 
gassing. Both processes result in the reduction of fuel retention in PFCs but via different mechanisms. Dynamic fuel retention occurs in PFCs from plasma wall interaction. 'In-situ out-gassing' is the in-vessel release of fuel from plasma loaded PFCs in the form of molecular hydrogen isotopes. Whereas 'ex situ out-gassing' occurs via isotopic exchange with water when PFCs are exposed to air on venting and is an on-going process for PFCs after removal. In-situ out-gassing will contribute to the reduction of fuel over the timescale of days to weeks from the end of plasma operations to the venting of the machine and has been shown to be $\propto \mathrm{t}^{-0.8}[5,26]$. However ex situ out-gassing will contribute on the timescale of 0.5-2 years before all components from an operating period are analysed. Ex-situ out-gassing on venting was measured following DTE1 when released T was measured using a water bubbler. Of the $35 \mathrm{~g}$ throughput of T in DTE1, the amount of T remaining in the vessel at the end of operations was $14 \mathrm{~g}$. This was reduced to $6.2 \mathrm{~g}$ after $\mathrm{D}$ and $\mathrm{H}$ cleaning. On venting the vessel a further $2 \mathrm{~g}$ of $\mathrm{T}$ was released 'ex situ out-gassing' [27], i.e., 6\% of the total injected T. Whilst there was no cleaning experiment at the end of the ILW3 operating period, loss of D from PFCs on venting is to be expected. Based on the experience of DTE1 this could be of the order of $1 / 3$ removed on venting. The effect of these out-gassing mechanisms on ex situ fuel retention analysis is currently being assessed and will be reported in the future. Similar conclusions regarding the differences in in situ and ex situ retention have been reported for Tore Supra [28] where significant fractions of fuel were released from PFCs during wall conditioning/cleaning, in situ out-gassing and venting.

\subsection{Operations}

Tritium inventory calculations are needed at various stages of the operational cycle; in situ T accumulation and accountancy, to inform the efficacy of T removal by cleaning methods and ex situ for assessing the handling of radioactive materials and waste liability. The T inventory assessment results in a total global inventory of $7.48 \times 10^{22}$ atoms and is summarised for the various components in table 1 . It assumes the $0.19 \%$ global retention rate and T throughput $3.94 \times 10^{25}$ atoms as discussed in section 2 . In terms of T accumulation and accountancy during JET T \& DT operations this method can be applied at any point in operations and form part of the overall accountancy which includes T injected into the JET vessel and T recovered to the Active Gas Handling System. This type of assessment will be ongoing until the end of T operations at JET.

The results in table 1 are also applicable for waste liability assessment, and with this in mind the material for each component type is listed for reference, although no further analysis relating to material type is discussed here. Since the results are based on ILW3 ex situ tile analysis the effect of T removal is not taken into account (as no fuel (D) removal operations took place at the end of ILW3). In this respect the assessment is higher than might be expected at the end of JET T \& DT operations where T removal is planned, and therefore provides a safety margin. A further safety margin could be applied by considering a higher $\mathrm{T}$ throughput of $4 \mathrm{~g}$ injected per day throughout T \& DT operations. This would increase the total throughput to $5.98 \times 10^{25} \mathrm{~T}$ atoms, with an associated global retention of $11.35 \times 10^{22}$ atoms. Note that this is not a factor two higher as it is only the 51 DT operating days where the daily $\mathrm{T}$ throughput has been increased to $4 \mathrm{~g}$, see section 2 .

To give some perspective on the efficacy of cleaning, isotopic exchange experiments with gas balance analysis have shown an accessible reservoir of $3 \times 10^{23}$ atoms in the ILW2 operating period [29]. Isotope exchange between $\mathrm{H}$ and $\mathrm{D}$ has also been demonstrated by ex situ analysis of $\mathrm{Be}$ and $\mathrm{W}$ components where $\mathrm{H}$ displaces $\mathrm{D}$ in components removed after ILW2 operations which ended in $\mathrm{H}$ plasmas and resulted in $\mathrm{H}$ rich surfaces [30]. During current JET operations $5.3 \times 10^{23} \mathrm{D}$ atoms were release from the vessel wall following baking, ion cyclotron wall cleaning and glow discharge experiments compared with $6.50 \times 10^{26} \mathrm{D}$ atoms injected between JPN 92505 to 98199 (from the start of plasma operations in 2018 to immediately prior to fuel removal experiments) [31]. A direct comparison of ex situ fuel retention and fuel removal operations is difficult to achieve for JET as there is no access to components until the end of operations. Therefore, the evaluation of the efficacy of fuel removal relies on previous ex situ and in situ fuel retention analysis. Considering the ex situ $0.19 \%$ retention, $1.24 \times 10^{24} \mathrm{D}$ atoms were retained prior to the fuel removal experiments which implies that $43 \%$ of this was removed by cleaning. However if $i n$ situ retention is higher, as discussed in section 4.1 , then this reduces the efficacy to $\sim 10 \%$. This supposes that all retained fuel is accessible for removal and that pre-existing inventory is not accessible. Although this is an oversimplification it does confirm that the fuel removal analysis does not exceed retention analysis predictions. Using the $\mathrm{D} / \mathrm{Be}$ ratio 0.07 , discussed in section 3 , it is possible to estimate the depth of the accessible reservoir in Be co-deposits. If $46.5 \%$ of the fuel removed is assumed to be in the codeposits at the top of the divertor, then $2.5 \times 10^{23} \mathrm{D}$ atoms are removed from $3.5 \times 10^{24} \mathrm{Be}$ atoms over an area $2.9 \mathrm{~m}^{2}$ (the area taking in Tile 0 and the top of Tile 1 to s coordinate $296 \mathrm{~mm}$ ). This results in a Be amount of $1.2 \times 10^{20} \mathrm{Be}$ atoms $/ \mathrm{cm}^{2}$, which is equivalent to $\sim 10 \mu \mathrm{m}$ for a fully dense layer. For DTE1 a high fraction of T was released where $14 \mathrm{~g}$ of retained $\mathrm{T}$ was reduced to $6.2 \mathrm{~g}$ after clean-up with $\mathrm{D}$ and $\mathrm{H}$ [27]. This clearly leaves a wide range which will be the subject of future analysis during the remaining JET T \& DT operations. 


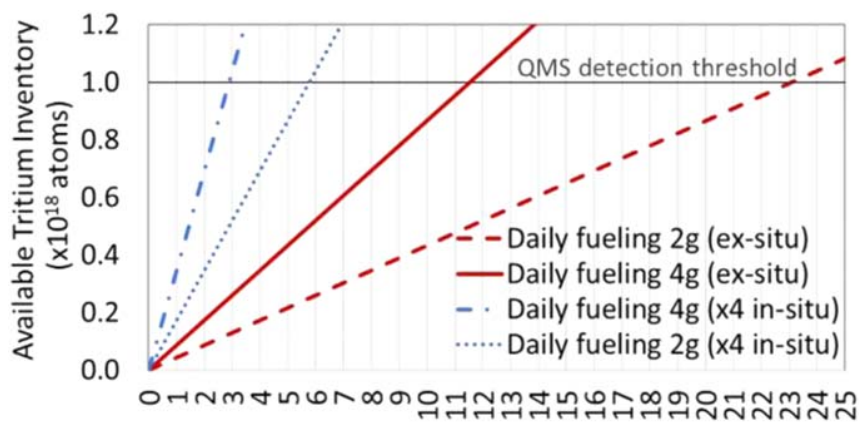

Days of Operation

Figure 2. LID-QMS operational cycle based on retention analysis of Tile 0.

\subsection{Design and operation of laser induced desorption diagnostic}

A Laser Induced Desorption diagnostic with detection by Quadrupole Mass Spectrometry (LID-QMS) is currently being designed for installation on JET. It is based on the experience of previous LID-QMS measurements [32-34]. It will be operational during DTE3 operations in 2023 and will demonstrate the capability for in situ fuel retention analysis including $\mathrm{T}$ as foreseen in ITER [10].

For the specific case of the LID-QMS diagnostic the ex situ analysis has provided data to facilitate a design solution for the laser specifications and laser beam rastering requirements needed to release sufficient fuel for detection by QMS, which is located approximately $2 \mathrm{~m}$ below the main vacuum vessel, $120^{\circ}$ toroidally from the target tile. The evaluation was based on the retention rate on the target tile, Tile 0 at the top of the inner divertor where the highest fuel retention occurs in the deposition zone between s-coordinates 60-150 mm, see figure 1 . In this region the areal concentration of D on Tile 0 was $5.36 \times 10^{18} \mathrm{D}$ atoms $\mathrm{cm}^{-2}$ when averaging all IBA, TDS and SIMS data. Assuming a ratio of $4.0 \times 10^{23}(2 \mathrm{~g}) \mathrm{T}$ atoms injected per day:2.2 $\times 10^{26} \mathrm{D}$ atoms injected in ILW3; the accumulating areal concentration of T on Tile 0 is $9.7 \times 10^{15} \mathrm{~T} / \mathrm{cm}^{2} /$ day. This provides the lower limit for daily $\mathrm{T}$ accumulation and therefore represents that most challenging retention rates on which to specify the laser rastering requirements and frequency of operating the diagnostic. The detection limit of the QMS has been investigated by a series of gas injections. To date the detection level achieved is $5 \times 10^{17} \mathrm{D}$ molecules injected into the JET vessel in a $0.5 \mathrm{~s}$ interval, detected as mass 4 molecules, this is equivalent to $1 \times 10^{18}$ atoms desorbed from deposits. The lowest detection limit has not yet been established due to insufficient time available on JET prior to moving to T operations. The achievable laser operating conditions are assumed to be $\sim 5 \mathrm{~cm}^{2}$ area rastered in $0.5 \mathrm{~s}$, with $0.07 \mathrm{~cm}^{2}$ spot at $140 \mathrm{~Hz}$ and $90 \%$ fuel removal efficiency. Based on these assumptions the $\mathrm{T}$ fuel available for desorption is given in figure 2 . In the worst case from ex situ analysis a change in $\mathrm{T}$ inventory at one location would only be detectable every 23 days. In the best case applying a factor 4 to take account of differences in in situ and ex situ retention rates as discussed in section 4.1, the detection interval reduces to 3-6 days. There are a number of factors that will affect these upper and lower limits presented in figure 2. Firstly, the in situ retention rate will decrease as in situ out-gassing will reduce fuel retention in PFCs. For example one hour after a JET pulse the pressure in the vessel decreases by more than an order of magnitude along with a reduction in mass $4\left(\mathrm{D}_{2}\right)$ detected by QMS which is indicative of decreasing fuel inventory in PFCs [5]. Secondly the detection limit of the QMS to the isotopic hydrogen molecules formed during desorption above the background out-gassing will pay a role. In the tests performed where $\mathrm{D}_{2}$ molecules are injected into JET we anticipate that the detection limit above the existing out-gassing background will be lower than currently established. In this case a factor 2 would result in the longest interval between detectable changes in retention reducing to 6-12 days for ex situ retention and 2-3 days for in situ retention. However, in the DT campaigns this assumption may not hold. It will depend upon the distribution of isotopic hydrogen molecules formed during the desorption process, $\mathrm{HD}, \mathrm{HT}, \mathrm{D}_{2}, \mathrm{DT}, \mathrm{T}_{2}$, and the background out-gassing in DT operations. Indeed, the interplay between the dynamic fuel retention, out-gassing and vacuum conditions needed for optimal operation of the LID-QMS diagnostic will finally be determined once installed. Despite these uncertainties, it should be noted that this assessment of the interval between detectable changes in fuel retention in one location does not prevent the LID-QMS diagnostic from being operated more frequently as different sampling areas may be targeted. In addition, it will not be necessary to wait for fuel to accumulate on the target tile as there will be D and T retained on the extant tile from earlier JET T \& DT operations. 


\section{Conclusions}

Ex-situ analysis of components removed from JET for the 2015-2016 ILW3 operating period are presented and the global retention as a percentage of the injected fuel determined as $0.19 \% \pm 0.08 \%$. The distribution of retained fuel also follows the established material migration pattern with $46.5 \%$ of the global fuel retention at the inner divertor predominantly in co-deposits on Tile 0 and Tile 1 . The retention in the divertor corners as a fraction of divertor retention has reduced by a factor $>2$ for ILW3 compared with ILW1. The ex situ retention rate remains lower than in situ retention rates determined from gas balance. Out-gassing in situ due to dynamic retention and on venting are likely to account for this difference.

The global and component-based retention fractions are used to assess future T retention based in JET T \& DT operations. These results are discussed in the context of T waste liability assessment and design and operation of LID-QMS diagnostic on JET. For the waste liability, this assessment provides an upper T retention, as T clean-up experiments which will take place at the end of T operations are not applied here. Cleaning experiments have shown to reduce fuel inventory by $43 \%$ when estimated from ex situ retention values, down to $\sim 10 \%$ if scaled for in situ retention and the depth of the accessible reservoir is $\sim 10 \mu \mathrm{m}$ in Be co-deposits. For the LID-QMS assessment the ex situ results provide a lower limit for T retention, which in turn provides a challenging criterion for achieving a design solution. Whilst estimation of retention from ex situ data provides lower retention rates than will arise in vessel, a scaling factor 4 has been applied for in situ analysis. However, this can be regarded as an upper retention rate limit, as in situ out-gassing will result in the reduction of in situ retention in PFCs.

The results show that the of ex situ analysis of PFCs plays a useful role in T retention analysis and will continue during JET T \& DT operations for accountancy purposes, quantification of T clean-up and monitoring of T waste liability.

\section{Acknowledgments}

This work has been carried out within the framework of the EUROfusion Consortium and has received funding from the Euratom research and training programme 2014-2018 and 2019-2020 under grant agreement No 633053 and from the RCUK [grant number EP/T012250/1]. To obtain further information on the data and models underlying this paper please contact PublicationsManager@ukaea.uk. The views and opinions expressed herein do not necessarily reflect those of the European Commission. The research used UKAEA's Materials Research Facility, which has been funded by and is part of the UK's National Nuclear User Facility and Henry Royce Institute for Advanced Materials.

\section{Data availability statement}

The data that support the findings of this study are available upon reasonable request from the authors. Contact PublicationsManager@ukaea.uk.

\section{ORCID iDs}

Anna Widdowson (iD https://orcid.org/0000-0002-6805-8853

J Paul Coad (10) https://orcid.org/0000-0001-8359-7073

Ionut Jepu (ib https:// orcid.org/0000-0001-8567-3228

Eduardo Alves (iD https://orcid.org/0000-0003-0633-8937

Norberto Catarino (iD https://orcid.org/0000-0003-3879-1533

Matej Mayer (iD https://orcid.org/0000-0002-5337-6963

Stepan Krat (1D https://orcid.org/0000-0001-6223-293X

Chris Rowley (iD https://orcid.org/0000-0001-6163-6836

Miroslaw Zlobinski (iD https://orcid.org/0000-0002-1395-7165

Marek Rubel (i) https://orcid.org/0000-0001-9901-6296

Kalle Heinola (10) https://orcid.org/0000-0002-0601-8274

Tom Wauters (1D) https://orcid.org/0000-0002-2941-7817

Laura Dittrich (iD https://orcid.org/0000-0003-1933-8186

Sunwoo Moon (10) https://orcid.org/0000-0002-0865-7387

Per Petersson (ib https://orcid.org/0000-0002-9812-9296

Aleksandra Baron-Wiechec (iD https://orcid.org/0000-0001-9458-6679 
Liga Avotina (iD https://orcid.org/0000-0001-5197-4196

\section{References}

[1] Joffrin E 2019 Nucl. Fusion 59112021

[2] Keilhacker M, Watkins M L and JET Team 1999 J. Nucl. Mater. 266-269 1-13

[3] Matthews G F et al 2007 Phys. Scr. TT128 137-43

[4] Widdowson A et al 2020 Phys. Scr. T171 014051

[5] Brezinsek Set al 2013 Nucl. Fusion 53083023

[6] Brezinsek Setal 2015 Nucl. Fusion 55063021

[7] Schmid Ketal 2015 Nucl. Fusion 55053015

[8] Romazanov J et al 2017 Phys. Scr. T170 14018

[9] Heinola Ket al 2016 Phys. Scr. T167 014075

[10] Reichle Ret al 2015 J. Nucl. Mater. 463 180-4

[11] Mayer Met al 2020 Nucl. Fusion 60025001

[12] Likonen Jet al 2019 Nucl. Mater. Energy 19300-6

[13] Lahtinen A et al 2019 Fusion Eng. Des. 146 1979-82

[14] Krat Setal 2020 Phys. Scr. T171 014059

[15] Catarino Net al 2020 Phys. Scr. T171 014044

[16] Dittrich LJET Contributors et al 2021 Submitt. to Phys. Scr. 96124071

[17] Moon Setal 2019 Nucl. Mater. Energy 1959-66

[18] Ström P et al 2019 J. Nucl. Mater. 516 202-13

[19] Widdowson A et al 2017 Nucl. Fusion 57086045

[20] Rubel Metal 2017 Nucl. Fusion 57066027

[21] Widdowson A et al 2016 Phys. Scr. 2016014057

[22] Krat Setal 2020 Phys. Scr. T171 014059

[23] Catarino N et al 2017 Nucl. Mater. Energy 12 559-63

[24] Likonen J et al 2009 J. Nucl. Mater. 390-391 631-4

[25] Loarer Tet al 2007 Nucl. Fusion 47 1112-20

[26] Philipps V etal 2013 J. Nucl. Mater. 438 S1067-71

[27] Peacock A T et al 2000 Fusion Eng. Des. 49-50 745-52

[28] Pégourié B et al 2013 J. Nucl. Mater. 438 120-5

[29] Loarer Tet al 2015 Nucl. Fusion 55043021

[30] Dittrich L et al 2021 47th Conf. on Plasma Physics (European Physical Society) http://ocs.ciemat.es/EPS2021PAP/pdf/O1.101.pdf

[31] Wauters Tet al 2021 18th Int. Conf. Plasma Facing Materials

[32] Schweer B et al 2007 J. Nucl. Mater. 363-365 1375-9

[33] Schweer B et al 2009 J. Nucl. Mater. 390-391 576-80

[34] Zlobinski M et al 2019 Fusion Eng. Des. 146 1176-80 